\title{
Elemental dynamics in porewater of an acid sulfate paddy soil as affected by sodium bentonite and dolomite amendments: insights from field study
}

\author{
Chalermchart Wongleecharoen ${ }^{1}$, Worachart Wisawapipat ${ }^{1}$, Daojarus $\operatorname{Ketrot}^{1}$, Natthapol Chittamart $^{1}$, \\ Surachet Aramrak ${ }^{1}$, Kittipon Chittanukul ${ }^{2}$, Rachit Sattapun ${ }^{2}$, and Saowanuch Tawornpruek ${ }^{1, *}$ \\ ${ }^{1}$ Department of Soil Science, Faculty of Agriculture, Kasetsart University, Bangkok 10900, Thailand \\ ${ }^{2}$ Project Environmental Management Department, PTT Public Company Limited, Bangkok 10900, Thailand
}

\begin{abstract}
Rice productivity in acid sulfate soils are frequently limited due primarily to strong acidity, low phosphorus $(\mathrm{P})$ availability and metal toxicity. A recent study has documented that the use of sodium bentonite $(\mathrm{NaB})$, non-hazardous material uses in natural gas pipeline construction, could be a promising soil amendment for mitigating major concerns experiencing in acid sulfate soils. Here we examined the effects of $\mathrm{NaB}$ and dolomite (DL) on dynamics in dissolved contents of both nutrient and associated elements in an acid sulfate soil and rice yield from paddy field in natural gas pipeline Rights-of-Way. The results demonstrated that the $\mathrm{NaB}$ and DL utilization significantly alleviated soil acidity and metal ( $\mathrm{Al}, \mathrm{Fe}$, and $\mathrm{Mn}$ ) toxicity $(\alpha=0.05$ ). Both soil amendments also significantly improved readily available P. Nonetheless, the soil NaB incorporation did elevate soluble sodium and did plummet soluble $\mathrm{K}, \mathrm{Ca}$, and $\mathrm{Mg}$. Therefore, appropriate ratios and amounts of the $\mathrm{K}, \mathrm{Ca}$, and $\mathrm{Mg}$ along with $\mathrm{N}$ fertilizers are indisputable needed to maintain the nutrient balance when applying $\mathrm{NaB}$ as a soil amendment. Our finding implies that combined use of $\mathrm{NaB}$ and DL are suggested to soil amendment and could alleviate nutrient imbalance as compared to the sole $\mathrm{NaB}$ utilization
\end{abstract}

\section{Introduction}

PTT Public Company Limited (PTT) is a national oil and gas company that has played an essential role in strengthening the national energy security of the Kingdom of Thailand by transporting natural gas via a pipeline system to customers, industrial and commercial sectors since 1981. PTT has been constructing and operating natural gas pipeline system network for more than 4,500 kilometers, including both onshore and offshore areas. Recently, PTT has been starting construction of the $5^{\text {th }}$ Transmission Natural Gas Pipeline Project (5TP) with approximately 415 kilometers in length from eastern to central part of Thailand, laid through various kinds of soils which is mostly acid sulfate soil that occurred in area around pipeline Rights-of-Way (ROW).

Acid sulfate soils are vital resources for crop production in the world. However, these soils have primary concerns from their acidity, metal toxicity, and basic cation deficiency. Globally, they occur of about 12-13 million ha, most of which extensively occupy in the tropics, especially in Southeast Asia [1]. In Thailand, these soils are widely distributed in the central plain area, which is being used for paddy rice cultivation. Therefore, rice productivity in these soils is rather scanty due mainly to their chemical limitation

Several measures have been adopted to alleviate soil acidity and metal toxicity in the soils, for example, neutralizing soil $\mathrm{pH}$ with liming materials such as limestone and dolomites (DL). In addition, sodiumbentonite $(\mathrm{NaB})$, an alkaline muddy material used in the Horizontal Directional Drilling (HDD) technique for 5TP project construction, has been recently documented to increase $\mathrm{pH}$ of acid sulfate soils at laboratory scale [2]. Nonetheless, the incubation experiment in oxic conditions is different from paddy rice fields, which are frequently subjected to flooded and non-flooded cycles during rice growth and harvest stages. The anoxic and oxic environments strongly affect changes in dissolved elements in soil porewater, representing the most available form of elements for plant uptake.

To elucidate the roles of $\mathrm{NaB}$ and DL amendments on paddy rice production, the primary goals of the present study are thus to 1) examine the changes in element concentration in pore-water of an acid sulfate soil amended with $\mathrm{NaB}$ and DL during paddy rice cultivation under field condition and 2) investigate the combined effect of $\mathrm{Na}$ bentonite and dolomite utilization on the productivity of

\footnotetext{
"Corresponding author: saowanuch.t@ku.th
} 
rice (Oryza sativa L., cv. RD43). Our results provide a possible measure of $\mathrm{NaB}$, a remnant from the natural gas pipeline construction activities, for enhancing paddy rice production in acid sulfate soils.

\section{Materials and methods}

\subsection{Field experiment}

The field trial was undertaken in an acid sulfate soil in 5TP project Right-of-Way, namely Rangsit series classified as Sulfic Endoaquepts according to USDA Soil Taxonomy. The value of soil $\mathrm{pH}$ before the experiment was 3.21, which is ultra-acidic. The trial was arranged into Randomized Complete Block Design (RCBD) with 4 treatments: control (T1) with no soil amendment, $\mathrm{NaB}$ utilization (T2) at a soil: $\mathrm{NaB}$ ratio of 1: 0.45 , combined $\mathrm{NaB}$ and DL utilization (T3) at a soil: NaB: DL ratio of 1:0.23:0.0047, and DL utilization (T4) at a soil: DL ratio of 1: 0.0095. For field applications, the ratio of $\mathrm{T} 2$ corresponded to the rate of $\mathrm{NaB}$ at $585 \mathrm{~T}$ $\mathrm{ha}^{-1}$ and the ratio of $\mathrm{T} 4$ matched with the rate of DL at 12.35 $\mathrm{T} \mathrm{ha}{ }^{-1}$, calculated from $10 \mathrm{~cm}$ depth and $1.3 \mathrm{~g} \mathrm{~cm}^{-3}$ bulk density of the studied soil. The applied $\mathrm{NaB}$ and DL rates were expected to raise soil $\mathrm{pH}$ to 6.0 based on the previous study [2]. The full details of chemical properties for these materials are given in Table 1 .

Table 1. Some chemical properties of bentonite $(\mathrm{NaB})$ and dolomite (DL) used in this experiment

\begin{tabular}{|c|c|c|}
\hline Parameter & $\begin{array}{c}\text { Bentonite } \\
(\mathrm{NaB})\end{array}$ & $\begin{array}{c}\text { Dolomite } \\
\text { (DL) }\end{array}$ \\
\hline $\mathrm{CCE}_{(\%)}$ & 32.7 & 126.1 \\
\hline $\mathrm{pH}(1: 10)$ & 9.74 & 9.59 \\
\hline $\mathrm{EC}_{\mathrm{e}}\left(\mathrm{dS} \mathrm{m}^{-1}\right)$ & 1.43 & 0.18 \\
\hline SAR & 28.8 & 0.4 \\
\hline ESP & 67.6 & 38.4 \\
\hline Exchangeable $\mathrm{Na}\left(\mathrm{mg} \mathrm{kg}^{-1}\right)$ & 70.5 & 0.3 \\
\hline Exchangeable $\mathrm{Ca}\left(\mathrm{mg} \mathrm{kg}^{-1}\right)$ & 25.0 & 40.6 \\
\hline Exchangeable $\mathrm{Mg}\left(\mathrm{mg} \mathrm{kg}^{-1}\right)$ & 14.6 & 5.6 \\
\hline Soluble $\mathrm{Na}\left(\mathrm{mg} \mathrm{kg}^{-1}\right)$ & 204.3 & 6.38 \\
\hline Soluble $\mathrm{Ca}\left(\mathrm{mg} \mathrm{kg}^{-1}\right)$ & 2.01 & 4.30 \\
\hline Soluble $\mathrm{Mg}\left(\mathrm{mg} \mathrm{kg}^{-1}\right)$ & 0.56 & 5.93 \\
\hline Total $\mathrm{N}\left(\mathrm{g} \mathrm{kg}^{-1}\right)$ & 0.39 & 0.37 \\
\hline Available $\mathrm{K}\left(\mathrm{mg} \mathrm{kg}^{-1}\right)$ & 279.7 & 8.7 \\
\hline Available $\mathrm{P}\left(\mathrm{mg} \mathrm{kg}^{-1}\right)$ & 4.6 & nd \\
\hline
\end{tabular}

The experiment was performed in four replicates. Each plot was divided by soil bunds with a plot size of $5 \times 4 \mathrm{~m}$. Before rice transplanting of 42 days, the $\mathrm{NaB}$ and DT materials had been thoroughly incorporated into each plot to ascertain soil acidity neutralization. Both amendments significantly increased soil $\mathrm{pH}$ and extractable bases $(\mathrm{Ca}$, $\mathrm{Mg}, \mathrm{Na}$, and $\mathrm{K}$ ), exchangeable sodium percentage (ESP) and sodium adsorption ratio (SAR) of the studied soil (Table 2). Subsequently, 20-day-old rice seeding of RD43 cultivar was transplanted to the plots with a spacing of
$20 \times 20 \mathrm{~cm}$. Basal fertilizers in the forms of urea $\left(\mathrm{CO}\left(\mathrm{NH}_{2}\right)_{2}\right)$ and diammonium phosphate $\left.\left(\mathrm{NH}_{4}\right)_{2} \mathrm{HPO}_{4}\right)$ were applied 14 days after transplanting, corresponding to the respective $\mathrm{N}$ and $\mathrm{P}$ rates of $19 \mathrm{~kg} \mathrm{~N} \mathrm{ha}^{-1}$ and $16 \mathrm{~kg} \mathrm{P} \mathrm{ha}^{-1}$. Topdressing $\mathrm{N}$ fertilizer ( $19 \mathrm{~kg} \mathrm{~N} \mathrm{ha}^{-1}$ ) was then applied 42 days after the transplanting

\subsection{Porewater sampling and analysis}

To examine changes in nutrient and relevant elements in the porewater of the acid sulfate soil amended with $\mathrm{NaB}$ and DL materials during the rice cultivation period, a rhizon sampler was deployed into surface soil of about 10 $\mathrm{cm}$ in each plot at the 45 degrees from the perpendicular expected to pass through rice roots. The aliquots were taken at 42, 56, 70, 84, 98, and 112 days after the soil amendment incorporation. The $\mathrm{pH}$ and $\mathrm{Eh}$ values had been concurrently measured after withdrawing aliquots from soils to minimize changes in Eh value from air oxidation.

The porewater samples were spiked with concentrated $\mathrm{HNO}_{3}(1 \% \mathrm{~V} / \mathrm{V})$ and then kept in the fridge at $4{ }^{\circ} \mathrm{C}$ before the quantification of plant nutrient $\mathrm{K}, \mathrm{Ca}, \mathrm{Mg}, \mathrm{Si}, \mathrm{P}, \mathrm{S}, \mathrm{Fe}, \mathrm{Mn}$, $\mathrm{Zn}, \mathrm{Cu}$, and $\mathrm{Ni}$ ) and other relevant elements ( $\mathrm{Na}$ and $\mathrm{Al}$ ) using Inductively Coupled Plasma Optical Emission Spectroscopy (Optima 8300 ICP-OES Spectrometer, PerkinElmer). The $\mathrm{pH}$ and $\mathrm{Eh}$ of the soil pastes were determined at the same days of the porewater sampling.

\subsection{Plant data collection}

At the harvest period of 12 weeks after the transplanted rice (126 days after the soil amendment incorporation), rice grain in each plot was taken and weighted. The rice weight was converted to $14 \%$ moisture content and reported as grain yield.

Table 2. Selected soil properties after 42 days of soil amendment incorporation.

\begin{tabular}{|c|c|c|c|c|c|c|c|c|}
\hline \multirow[b]{2}{*}{ Treatment } & \multirow{2}{*}{$\begin{array}{c}\text { Soil } \\
\text { pH } \\
(1: 1)\end{array}$} & \multirow{2}{*}{$\begin{array}{r}\mathbf{E C}_{\mathbf{e}} \\
\left(\mathbf{d} \mathbf{S}^{-\mathbf{1}}\right)\end{array}$} & \multicolumn{4}{|c|}{ Extractable bases } & \multirow[b]{2}{*}{ ESP } & \multirow[b]{2}{*}{ SAR } \\
\hline & & & $\begin{array}{c}\mathbf{C a} \\
(-\end{array}$ & $\begin{array}{c}\mathrm{Mg} \\
\mathrm{mg} \mathrm{k}\end{array}$ & $\begin{array}{c}\mathrm{Na} \\
\mathrm{kg}^{-1}\end{array}$ & K & & \\
\hline $\begin{array}{c}\mathrm{T} 1 \\
\text { (Control) }\end{array}$ & $3.13^{\mathrm{b}}$ & 4.2 & $441^{\mathrm{c}}$ & $249^{d}$ & $103^{c}$ & $202^{b}$ & $3.0^{\mathrm{c}}$ & $0.5^{\mathrm{c}}$ \\
\hline $\begin{array}{c}\mathrm{T} 2 \\
(\mathrm{NaB})\end{array}$ & $5.95^{\mathrm{a}}$ & 3.7 & $3,245^{\mathrm{a}}$ & $1,412^{c}$ & $5,188^{a}$ & $301^{\mathrm{a}}$ & $44.6^{a}$ & $31.5^{\mathrm{a}}$ \\
\hline $\begin{array}{c}\mathrm{T} 3 \\
(\mathrm{NaB}+\mathrm{DL})\end{array}$ & $6.00^{\mathrm{a}}$ & 3.7 & $3,498^{a}$ & $1,808^{b}$ & $3,483^{\mathrm{b}}$ & $349^{\mathrm{a}}$ & $31.4^{\mathrm{b}}$ & $8.1^{\mathrm{b}}$ \\
\hline $\begin{array}{c}\mathrm{T} 4 \\
(\mathrm{DL})\end{array}$ & $5.24^{\mathrm{a}}$ & 4 & $2,149^{\mathrm{b}}$ & $2,137^{\mathrm{a}}$ & $305^{\mathrm{c}}$ & $335^{\mathrm{a}}$ & $3.2 \mathrm{c}$ & $0.4^{\mathrm{c}}$ \\
\hline F-test & * & ns & * & * & $*$ & * & * & * \\
\hline$\overline{\mathrm{CV}}(\%)$ & 9 & 22 & 21 & 11 & 18 & 21 & 13 & 25 \\
\hline
\end{tabular}

Different letters in the same columns are significantly different at $\alpha=0.05$.

\section{Results and discussion}




\section{$3.1 \mathrm{pH}$ and Eh dynamics}

Soil $\mathrm{pH}$ in all treatments tended to decrease during the entire periods of rice cultivation (Fig. 1). Time average value of $\mathrm{pH}$ in the control treatment was lowest $\mathrm{pH}=3.20$ ), whereas the other treatments were significantly higher. The $\mathrm{pH}$ value for the $\mathrm{NaB}$ treatment (T2) was higher than that of the DL treatment (T4).

Both soil $\mathrm{NaB}$ and $\mathrm{DL}$ amendments significantly affected the changes in soil Eh values (Fig. 1). The Eh
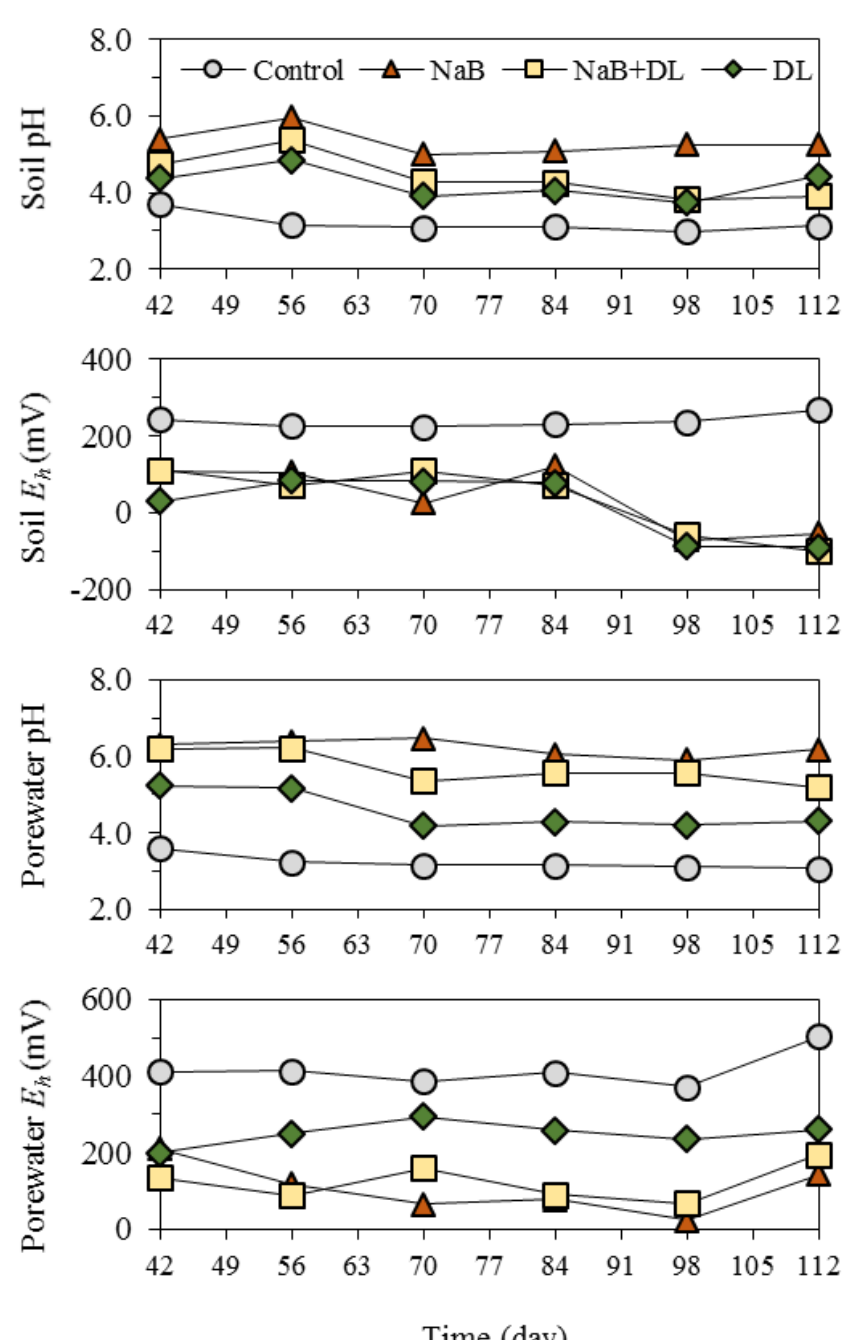

Time (day) values in both treatments decreased with the rice growth period, indicating the soil reduction. However, the Eh value in the control treatment remained stable, reflecting the soil was under suboxic conditions. The unexpected Eh fluctuations across the treatments could be attributable to the ultra-acidity in the control treatment that could inhibit microbial activity and limit soil reduction. The $\mathrm{pH}$ and $\mathrm{Eh}$ values in porewater showed somewhat similar patterns to soils that had a decrease in the $\mathrm{pH}$ and Eh with time.
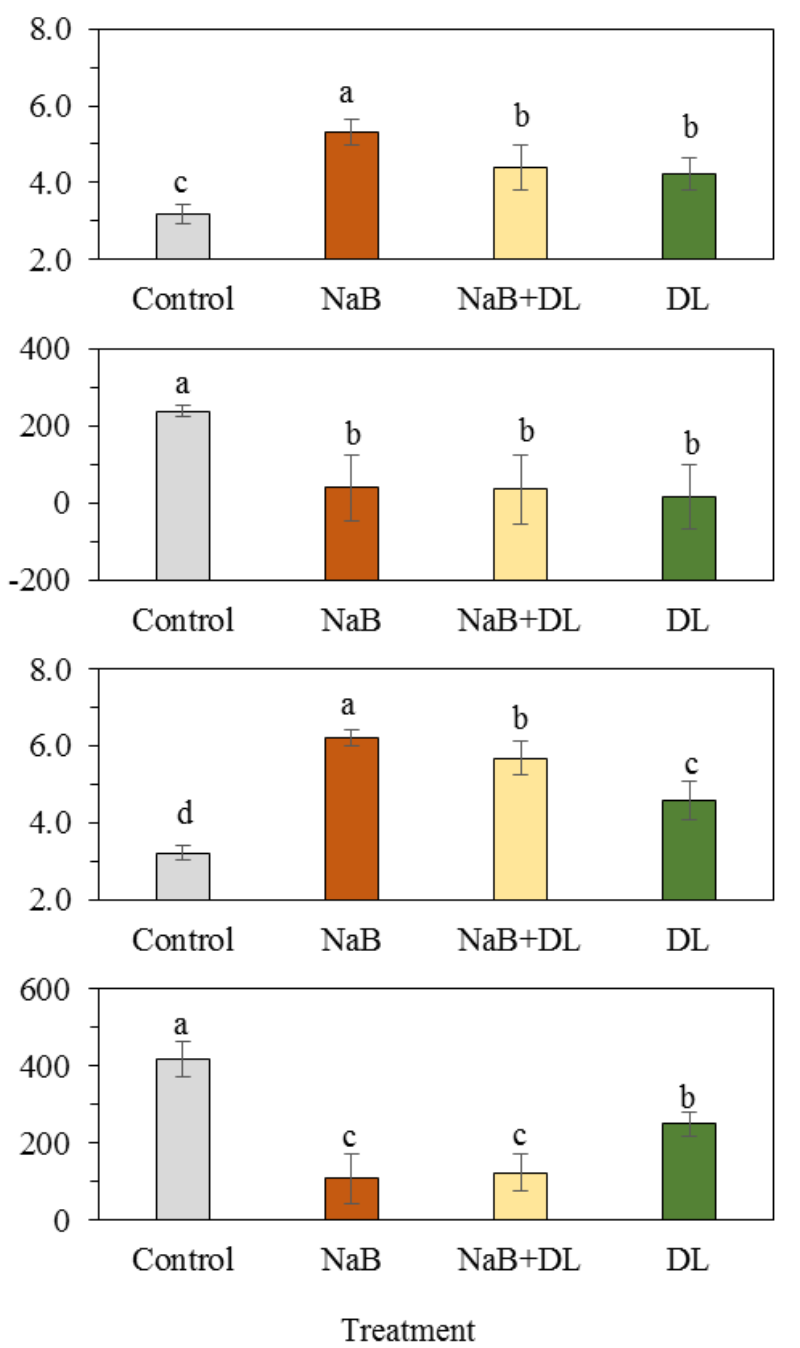

Fig. 1. Time-function (left panel) and time-average values (right panel) of $\mathrm{pH}$ and Eh of soil and porewater during the entire period of rice (Oryza sativa L., cv. RD43) grown in an acid sulfate soils amended with sodium bentonite (NaB) and dolomite (DL). Different letters above columns are significantly different at $\alpha=0.05$.

\subsection{Porewater dynamics}

Dynamics of essential nutrient elements $(\mathrm{K}, \mathrm{Ca}, \mathrm{Mg}, \mathrm{Si}, \mathrm{P}$, $\mathrm{S}, \mathrm{Fe}, \mathrm{Mn}, \mathrm{Zn}, \mathrm{Cu}$, and $\mathrm{Ni}$ ) and associated relevant elements ( $\mathrm{Na}$ and $\mathrm{Al}$ ) in porewater of the studied acid sulfated soils incorporated with $\mathrm{NaB}$ and DL compared to the control treatment are given in Figs 2 and 3. The results showed somewhat intricate patterns (i.e., increased, decreased or stable) of dissolved elements among treatments against the rice growing period. In the control treatment with no soil amendment (T1), some elements including $\mathrm{K}, \mathrm{Ca}, \mathrm{Mg}, \mathrm{P}, \mathrm{S}, \mathrm{Al}, \mathrm{Fe}, \mathrm{Mn}, \mathrm{Zn}$, Ni were likely to elevate with the flooding period, whereas the dissolved $\mathrm{Cu}$ demonstrated a clear reverse trend. The dissolved $\mathrm{Na}$ was stable upon the flooding. These deviations could be attributed to chemical processes including i) the releasing of adsorbed elements located inside mineral interlayers, ii) reductive dissolution of redox-sensitive elements (e.g., Fe, 
and $\mathrm{Mn}$ ), and iii) releasing of elements adsorbed to $\mathrm{Fe} / \mathrm{Mn}$ oxide induced by the reductive dissolution [3]. A previous study showed that the dominant clay mineral of acid soil in this area was smectite [4, 5], a highly expanding phyllosilicate, which had high capability to adsorb substantial amount of water in its interlayer and eventually released the adsorbed ions into the soil solution.

\subsection{Time-average porewater}

The time-average contents of the elements were calculated in order to gain inclusive interpretation of the effect of $\mathrm{NaB}$ and $\mathrm{DL}$ on the contents of relevant elements in porewater. The results demonstrated that $\mathrm{NaB}$ utilization decreased concentrations of metals, including $\mathrm{Al}, \mathrm{Fe}$, and $\mathrm{Mn}$ that are highly toxic and limit crop productivity in acid sulfate soils. The $\mathrm{NaB}$ treatment also increased dissolved $\mathrm{P}$, which is likely to be a consequence of soil $\mathrm{pH}$ increment. However, this material deteriorates several essential macronutrients, including $\mathrm{K}, \mathrm{Ca}$, and $\mathrm{Mg}$ as well as a beneficial element for rice that is $\mathrm{Si}$. Furthermore, dissolved $\mathrm{Na}$ concentration in the $\mathrm{NaB}$ treatment was higher than the control treatment of 5.9-fold. The increase of $\mathrm{Na}$ and the decrease of $\mathrm{K}, \mathrm{Ca}$, and $\mathrm{Mg}$ in the porewater after the $\mathrm{NaB}$ incorporation should be taken into a thoughtful consideration that nutrient imbalances could be experienced. Therefore, the use of $\mathrm{NaB}$ for soil amendment must be combined with proper management of nutrients.

For the DL treatment, the decreased concentrations of $\mathrm{Si}, \mathrm{Al}, \mathrm{Fe}, \mathrm{Mn}, \mathrm{Zn}$, and Ni were observed, along with the increase of dissolved $\mathrm{P}$. This again could be attributed to soil acidity alleviation from its liming effect. There were no significant differences in dissolved $\mathrm{Ca}$ and $\mathrm{Mg}$ in the DL treatment compared to the control treatment.

The combined uses of $\mathrm{NaB}$ and DL amendments (T3) had both effects of these materials that are decreasing metal toxicity, increasing soil $\mathrm{pH}$ and $\mathrm{P}$ availability, and lowering $\mathrm{K}, \mathrm{Ca}$, and $\mathrm{Mg}$ availability. This treatment $(\mathrm{NaB}+\mathrm{DL})$ less deteriorated the macronutrient availability than the sole $\mathrm{NaB}$ utilization (T2).

\subsection{Rice yield}

The rice grain yield in the control treatment was unobtainable (Fig. 4.), which is due to a very strong acidity of the studied soil with the high toxicity of several metals including $\mathrm{Al}, \mathrm{Fe}, \mathrm{Mn}$, and Ni. However, the use of both soil amendments (NaB and $\mathrm{DL}$ ) had a significantly positive effect on rice yield. This obtained yield resulted from the alleviation of soil acidity and metal toxicity along with enhancing soil nutrient availability. There was no statistical difference in rice yield between the $\mathrm{NaB}$ and DL treatments, which is due to the soil inversion during the land preparation caused a heterogeneity of soil materials in each plot. The DL application tended to provide a higher yield than the $\mathrm{NaB}$ treatment.

\section{Conclusions}

Our results demonstrated that the studied acid sulfate soil was ultra-acidic $(\mathrm{pH}=3.21$ ), which soil $\mathrm{pH}$ remained constant throughout the entire period of rice production (vegetative and grain-filling stages). The strong acidity exaggerated a high solubility of several metals including $\mathrm{Al}, \mathrm{Fe}, \mathrm{Mn}, \mathrm{Zn}$, and $\mathrm{Ni}$, and could induce the death of rice (Oryza sativa L., cv. RD43). The sole utilization of sodium bentonite $(\mathrm{NaB})$ and dolomite $(\mathrm{DL})$ or the combined uses of both materials can raise soil $\mathrm{pH}$, demote metal toxicity, and promote phosphorus $(\mathrm{P})$ availability. These beneficial effects rehabilitated rice growth and productivity. The soil $\mathrm{NaB}$ incorporation could suppress the availability of essential plant nutrients ( $\mathrm{K}, \mathrm{Ca}, \mathrm{Mg}$ ) and considerably enhance the soluble magnitude of sodium (Na). Therefore, the use of the $\mathrm{NaB}$ material must be stipulated that adequate $\mathrm{K}, \mathrm{Ca}$, and $\mathrm{Mg}$, along with $\mathrm{N}$ fertilizers, are needed to be applied to prevent nutrient imbalance. The combined use of DL and $\mathrm{NaB}$ could in part alleviate $\mathrm{Ca}$ and $\mathrm{Mg}$ imbalance as compared to the sole $\mathrm{NaB}$ utilization. Nonetheless, the suitable ratio of $\mathrm{NaB}$ and DL materials along with $\mathrm{N}$ and $\mathrm{P}$ fertilizers for improving rice productivity in such acid sulfate soils are required for further investigation. 

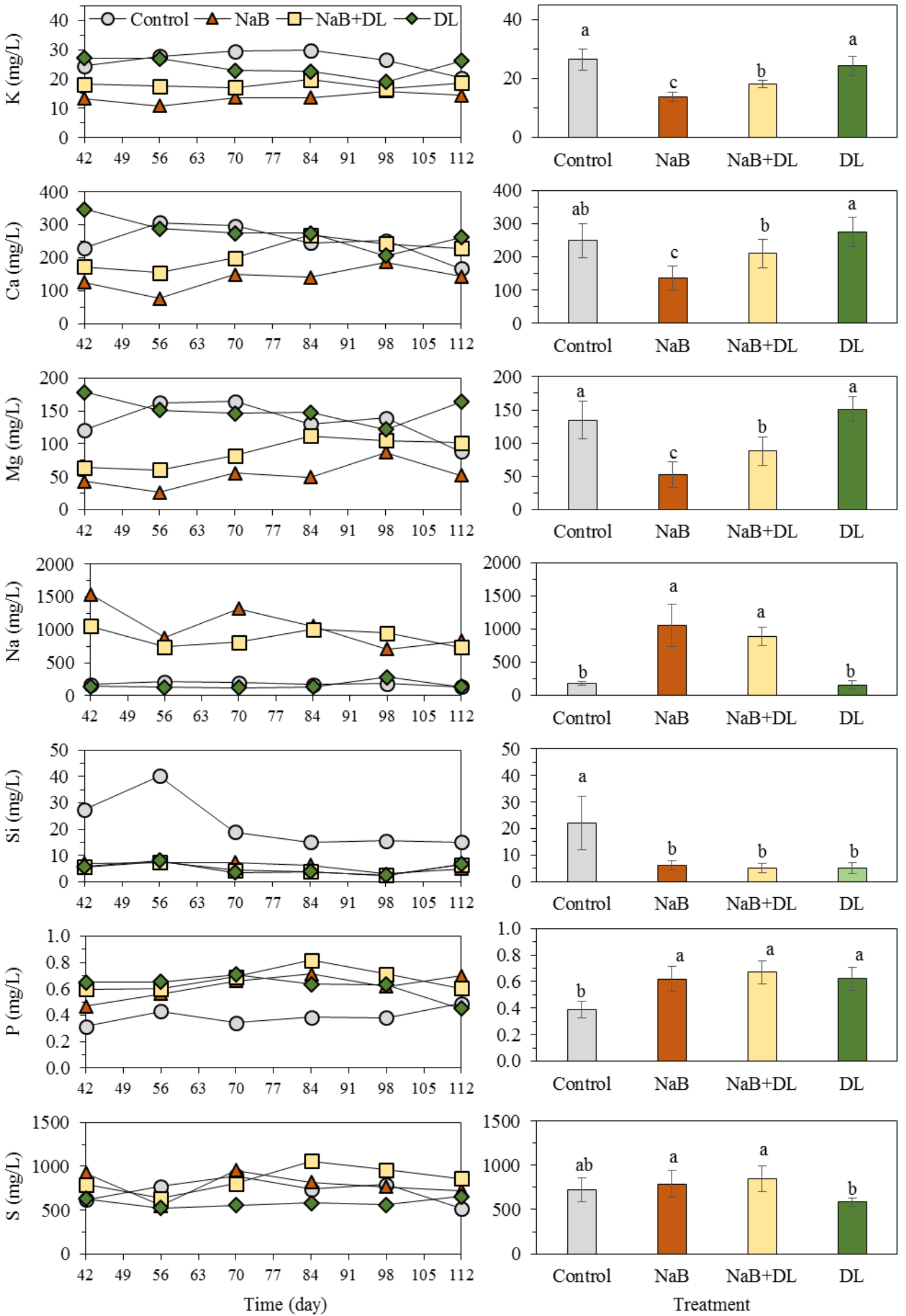

Fig. 2. Time-function (left panel) and time-average values (right panel) of dissolved $\mathrm{K}, \mathrm{Ca}, \mathrm{Mg}, \mathrm{Na}, \mathrm{Si}$, $\mathrm{P}$, and $\mathrm{S}$ in porewater during entire period of rice (Oryza sativa L., cv. RD43) grown in an acid sulfate soils amended with sodium bentonite $(\mathrm{NaB})$ and dolomite (DL). Different letters above columns are significantly different at $\alpha=0.05$. 

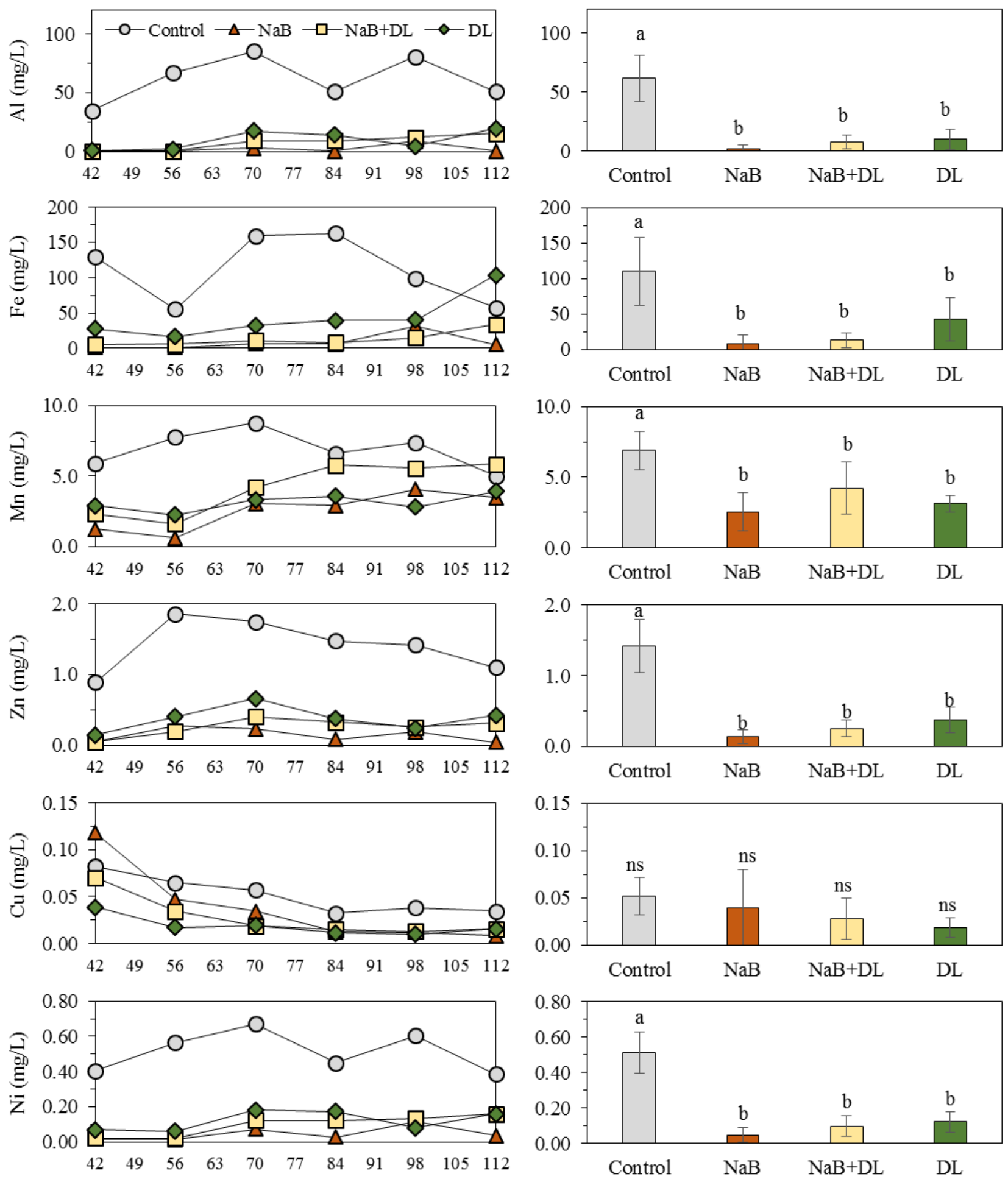

Time (day)

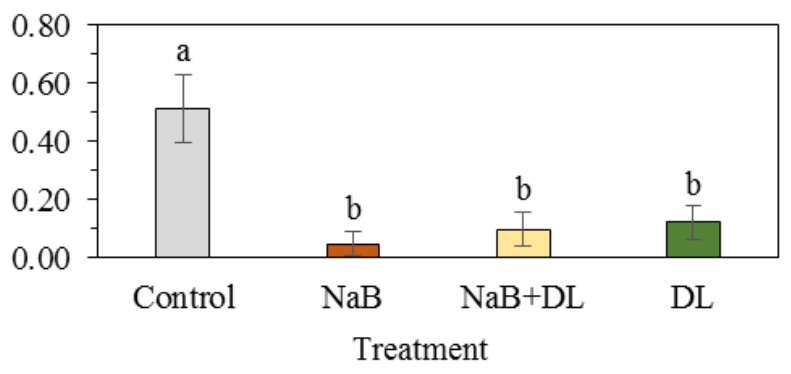

Fig. 3. Time-function (left panel) and time-average values (right panel) of dissolved $\mathrm{Al}, \mathrm{Fe}, \mathrm{Mn}, \mathrm{Zn}, \mathrm{Cu}$, and $\mathrm{Ni}$ in porewater during the entire period of rice (Oryza sativa L., cv. RD43) grown in an acid sulfate soils amended with sodium bentonite (NaB) and dolomite (DL). Different letters above columns are significantly different at $\alpha=0.05$. 


\section{References}

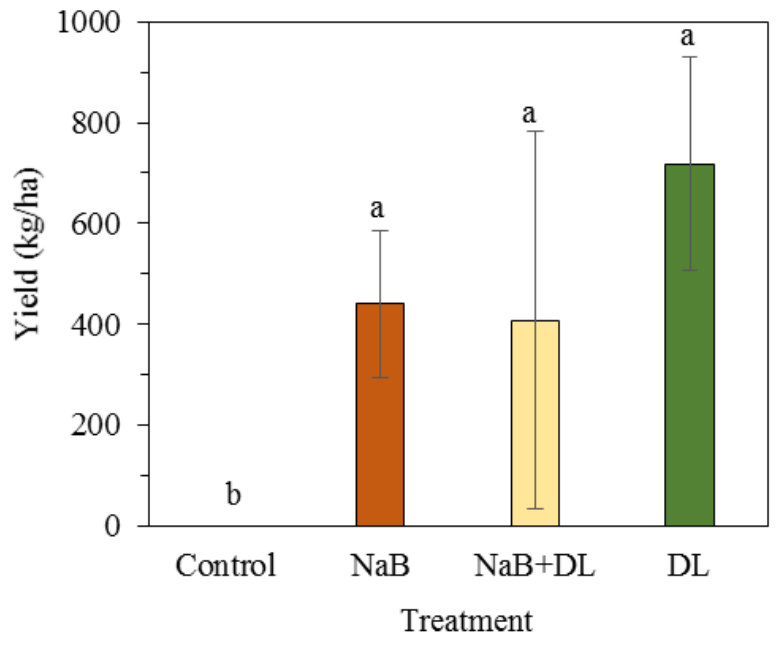

Fig. 4. The yield of rice (Oryza sativa L., cv. RD43) grown in an acid sulfate soils amended with sodium bentonite $(\mathrm{NaB})$, combined $\mathrm{NaB}$ and dolomite (DL), and DL compared to the control treatment. Different letters above columns are significantly different at $\alpha=0.05$.
1. Andriesse W and Van Mensvoort M 2006 Acid sulfate soils: distribution and extent Encyclopedia of Soil Science 1 14-9

2. Chittamart N, Tawornpruek S, Ketrot D, Aramrak S, Chittanukul K and Sattapun R 2018 Utilization of Nabentonite to Improve pH-buffering Capacity of Acid Sulfate Soils in Natural Gas Transmission Pipeline Rights-of-Way, Thailand. In: IOP Conference Series. Earth and Environmental Science: IOP Publishing) p 012023

3. Borch T, Kretzschmar R, Kappler A, Cappellen P V, Ginder-Vogel M, Voegelin A and Campbell K 2010 Biogeochemical redox processes and their impact on contaminant dynamics Environ Sci Technol 44 15-23

4. Janjirawuttikul $\mathrm{N}$, Umitsu $\mathrm{M}$ and Tawornpruek $\mathrm{S}$ 2011 Pedogenesis of acid sulfate soils in the lower central plain of Thailand Int. J. Soil Sci. 6 77-102

5. Chittamart N, Suddhiprakarn A, Kheoruenromne I and Gilkes R J 2010 Layer-charge characteristics of smectite in Thai vertisols Clays Clay Miner. 58247 62 